\title{
MANAGING CROSS-CULTURAL DIFFERENCES IN MULTINATIONAL CORPORATIONS OF THAILAND
}

\author{
Shiva Rajpal \\ Irina V. Onyusheva
}

\begin{abstract}
Stamford International University, Thailand, Bangkok
As corporations expand and their business activities increase, their focus is not limited only to the local geographic region but to the world. This, in turn, has led to the emergence of multinational corporations, sometimes called transnational corporations or even global firms. With the advent of new political ideologies, multinational corporations have found their firm footing all around the world. Having a cross-cultural team can help in providing a varied experience and advanced thinking in the establishment of competitive position among organizations. Definitely, there could be some interference in completing projects due to this diversity but the manager should be better equipped to face this challenge so that to avoid and prevent cultural misunderstandings. In this paper we will try to look at some of the theories related to cross-cultural management and some methods such as motivational training of employees dealing with the related issues. The paper shows that global project management can succeed through culturally aware leadership, cross-cultural communication, and mutual respect.
\end{abstract}

Keywords: multinational corporations; cross-cultural communication; globalization; expatriates.

\section{Introduction}

While considering large corporations we can easily see that many of them have wide economic, political and social clouts in the countries of their functioning. Moving from one country to another helps corporations get a regional advantage as compared to its rivals in

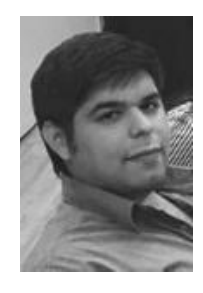

\section{Shiva Rajpal}

Stamford International University, International MBA Program

Interests - International Business Management, Strategic Management, Corporate Governance

Email: om2362@gmail.com

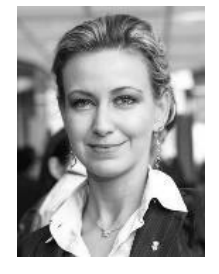

\section{Irina V. Onyusheva}

Stamford International University, Dr., Prof.

Interests - Economics, Strategic Management, Formation, ensuring and increasing economic competitiveness on both micro- and macro- levels; Human Capital development; HR Management; Knowledge Economy; Knowledge Management; Project Management; Management in Education

E-mail: irina.onyusheva@stamford.edu 


\section{MANAGING CROSS-CULTURAL DIFFERENCES IN}

the region, and this leads to overall blooming of multinational corporations worldwide. Managers in today's multicultural global business community frequently encounter cultural differences, which can impede the successful completion of projects. Globalization has contributed to the growing integration of the world economy via business activities of countless international firms.

Advances in technology and falling barriers in trade and investment are the main forces driving globalization. Both these factors have increased the ease and the speed with which companies manage their operations today. These forces have made the cost of international business affordable for all types of firms. Consequently, multinational corporations are currently facing more intense pressure from competition and are compelled to respond to global challenges.

There are different approaches to setting cultural dimensions along which dominant value systems can be ordered. The value systems affect our thinking, feeling, and acting as well as behavior of organizations and institutions. Investing and running business overseas involves more risk than undertaking domestic business. Among all international business risks, cross-cultural discrepancies are inevitable in particular because human resources are required at all operational levels and across all business units. Therefore, there is a need to effectively manage the cross-culture aspect of human resources for the success of international organizations.

An important fact, however, is that culture as such is a complex phenomenon. Understanding cultural differences and following only mandatory "do's and dont's" communication guidelines while doing business in various countries may not be sufficient to guarantee success in managing international business communication problems, especially for those who cannot overcome ethnocentrism (which is a conscious or subconscious belief that one's own culture is better than all other cultures). It is worthwhile investigating how shared multicultural norms and values can be developed and acted upon among people working in organizations in which business structures and cultural environments are characterized as multinational, global, or transnational.

As we know, individuals who work in such diverse cultural environments usually have their own code language (i.e., a specific set of norms and values) with their own cultural background. In this study, foreign companies in Thailand are in the centre of attention. The purpose for this study is to provide insightful information regarding international/intercultural communication issues, along with management tactics for handling such problems occurring in the international business settings in foreign companies operating in Thailand. Content of this article can be beneficial and useful for both expatriates and Thai employees who are trying to perceive and learn each other's understandings, needs, and expectations. The objective is to provide a clear picture and elaborate a better understanding of how expatriate managers can gain sincere willingness and full cooperation while dealing with local Thai employees. Information presented in this paper has been obtained through exclusive interviews and questionnaires, all data were collected in Bangkok, Thailand.

This study focuses on organizational culture that, in general, reflects the practices people working in the same organization. Organizational culture consists of a set of symbols and ceremonies that show the underlying values and beliefs of an organization in relation to its employees. The process of organizational culture formation is influenced by corporate environment. Profile of a culture in large companies is different from their smaller counterparts. It is not mandatory for organizations with similar nature of business and 
national culture to have organizational cultural commonalities too. Each organization's culture is unique; however, there are still some similar aspects. People who are new follow the pattern of the organizational culture as the way to join the organization smoothly as well as to socialize in the company more quickly and effectively. The shared issues such as attitudes, beliefs and ethics formed in the course of previous events by senior members convey to new members in an organization what is the organizational culture here as well as structure and purpose, climate and individual beliefs shaping this organizational culture. If the members' shared values, changeability, strategically appropriate practices are highly valued by leadership and membership at all levels, the organizational culture would be be more effective.

\section{Literature Review}

Large corporations stand out as economic, political, environmental, and cultural powers, without which today's globalized world is already hard to imagine. Corporations have direct impact on the lives of billions of people every day, often in complex and imperceptible ways (Roach, 2007).

Furthermore, Roach states that the growth of these corporations is typically measured in economic terms - profits, assets, number of employees, and stock prices. However, the impact of global corporations extends well beyond the economic realm. The production decisions of large firms have significant environmental implications at the national and global levels. Corporations exert political influence to obtain subsidies, reduce their tax burdens, and thus shape public policy. Corporate policies on wages, working conditions, and benefits affect the quality of life for millions of people. Some people think that the ascendancy of global corporations as a positive force, bringing economic growth, jobs, lower prices, and quality products to an expanding share of the world's population.

Many view large firms as exploiting workers, dominating the public policy process, damaging the natural environment, and degrading cultural values. One thing is for certain global corporations are an inescapable phenomenon in the modern world and will continue to be so in the foreseeable future. Two leading studies of cross-cultural management have been conducted by Geert Hofstede and Fons Trompenaars (1997). They proposed a set of cultural dimensions along which dominant value systems can be ordered. Many of these value systems affect human thinking, feeling, and acting, and the behavior of organizations and institutions in predictable ways. The two sets of dimensions reflect almost similar elementary problems that any society has to cope with but for which solutions differ. They are similar in some respects and different in others. The dimensions can be grouped into several categories:

1) Relations between people. Two main cultural differences have been identified. Hofstede distinguishes between individualism and collectivism.

2) Motivational orientation. Societies choose the ways to cope with the inherent uncertainty of living.

3) Attitudes towards time: The difference in perception of time period which is longterm and a short-term time period. It is difficult to fully control the outcomes of one's actions and, therefore, trying too hard to achieve something and making long-term plans are not worthwhile exercises.

Cross-cultural management is obviously important and has a great effect on the success of overseas business operations. Cullen and Parvoteeah (2008) have reported that 


\section{MANAGING CROSS-CULTURAL DIFFERENCES IN}

international business management is inseparable from the sphere of patterned cultural behaviors because culture is represented in terms of the pervasive and common beliefs, norms, values, and symbols that guide the everyday life of different groups of people. Managers in multinational companies have to decide to choose and adjust their strategies aligned with each country's culture. Appropriate business strategies can be used to reduce possible risks and impacts from cross-cultural discrepancies so that to deliver successful outcomes for enterprises.

According to (Cullen and Parboteeah, 2008), culture can be generally classified into three major levels: (i) national Culture - the dominant culture within political boundaries of a nation-state; (ii) business culture - values, norms, and beliefs that pertain to business in a culture (i.e., acceptable ways to conduct business in a society); and (iii) occupational and organizational culture.

Occupational culture refers to beliefs, norms, values, and expected ways of behaving for people in the same occupational group, while organizational culture is the set of important understandings that members of an organization share. All of the levels in crosscultural differences affect all business interactions and business performance overall. In an increasingly global business environment, investors from around the world expanded to the markets of Southeast Asia, Thailand especially, in the late 1980s.

The past several years the volume of Thailand's trade with the rest of the world has been increasing dramatically, reaching more than US\$9 bln (The Thailand Board of Investment, 2008). It has created a large numbers of job opportunities for the Thai (Institute of Asia Study, 2005). Smith et al. (2008) presents a conceptual framework on the factors affecting cross-country differences. This framework is associated with economic development, political/social history, and national cultures (norms, values, and beliefs), which has a powerful influence on social norms and the role of an organization, as well as social character traits (values, role definitions, motivations, and perceptions).

These have influenced organizational citizenship behavior (OCB) and have had an important impact on organizational outcomes such as organizational performance, team performance, and individual performance ratings. In the meantime, moreover, there are several antecedents that also affect OCB, such as organizational contexts, attitudes etc. Measurement and studies on culture in an organization helps boosting business productivity. Culture has an important effect to the performance of an organization as well as on individual satisfaction. Employees who are well aware about the career path details within an organization have more job satisfaction, and are more easily socialized into the prevailing culture. Organizations with higher levels of employee involvement are more effective.

The not so well structured organizational culture leads to lower commitment and less willingness among employees to do their jobs correctly and pay attention to details. Asian cultures are generally categorized as high-context cultures. The opposite to that is lowcontext culture, in which nonverbal messages are much more important and being used just like verbal communication in high-context cultures. Members in high-context cultures do not obviously show any feelings about things surrounding them.

Managers should be aware of the cross-cultural differences in working environment in order to facilitate mutual adjustment in cross-cultural gaps (Hofstede, 2001). Many companies dispatch their employees overseas to implement global corporate strategies and manage subsidiaries (Windham International, 1998), and it was found that managers from a parent culture have difficulties while trying to fit into a host culture (Kim, 2004), while local 
staff also has difficulties adapting to their managers (Bennett et al., 2000). This can cause problems with performance which can affect company's profits directly (Kim, 2008).

The importance of expatriates for multinational corporations' operations has been wellestablished in literature (Brewster and Scullion, 1997; Bonache et al., 2001). Management of expatriates (including the practices of selection, training, and compensation practices) and the factors contributing to expatriates' success have been investigated in research literature quite extensively (for example, Tung 1982; Mendenhall, Dunbar and Oddou, 1987; Caligiuri 2000a, 2000b).

While past research studies provide a rich foundation for understanding management and contribution of expatriates, there are only a few research studies which identify how expatriate levels are determined within MNCs (e.g., Delios and Bjorkman, 2000 or Harzing, 2001) and how these expatriate staffing practices relate to the performance of subsidiaries (Gong 2003). There is a need for further investigation so that to understand better the factors that come into play when multinational corporations are staffing their subsidiaries and how expatriate staffing relates to subsidiary-level outcomes such as performance (Schuler, Budhwar and Florkowski 2002).

Relying on the transaction costs theory, the primary goal of this study is to assess the influence of expatriates on the subsidiary-level performance as a function of cultural distance between a home and a host country. While cultural distance increases the propensity to staff subsidiaries with expatriates, it may also magnify the disadvantages of using expatriates leading to lower subsidiary performance. Thai employees often do not show strong enough commitment when it comes to tasks assigned. Thai employees never say they cannot do the work when it is assigned to them and they never ask for help when they experience any sort of problems. This often leads to situations when expatriate managers are informed at the very last minute that their Thai staff could not do the work or could not finish it within the time expected.

International business requires special knowledge, commitment of resources, and considerable time to reach success in foreign operations. Being large organizations, multinational enterprises are not constrained by limited financial or human resources. Hence, this research places substantial emphasis on the case study of a leading multinational enterprise producing and distributing consumer products and successfully expanding across national borders. The company has been able to create a competitive advantage to outperform its competitors, both locally and internationally, by managing effectively its vast human resources across national and cultural boundaries.

Selmer (2000) found that satisfaction has a positive effect on individual performance, and the two-factor theory established by (Herzberg, 1959) states that motivational factors increase satisfaction in a job place. However, two-factor theory has its limitations in explaining satisfaction when it comes to cross-cultural working environment. Thus, this study adopts Shih and Chinerawat's econometric model (2009), which incorporated demographic factors into the preexisting two-factor theory to explore the cross-cultural working satisfaction and how it is affecting multinational companies' performance.

\section{The research problem, goal and objectives}

The research problem here concerns the fact that most of researched study cases have been performed on the data of expatriate managers in Latin America, China (Gao, 2005) and 


\section{MANAGING CROSS-CULTURAL DIFFERENCES IN}

Korea (Kim, 2009). Very few studies focus on multinational companies in Thailand (Shih \& Chinerawat, 2009). Consequently, this research will provide evidence on Thailand business environment and more specifically - on the cross-cultural differences that exist in multinational corporations.

The main goal of the research is help smooth the cross-cultural differences in multinational corporations operating in Thailand.

To achieve this research goal the following objectives have been set forward:

(1) to study cross-cultural management field by exploring international management in Thailand;

(2) to analyze the econometric model so that to find which factors impact cross-cultural working satisfaction;

(3) using the obtained empirical results, to suggest different approaches to managing employees and assisting managers in reaching high level of satisfaction among their employees.

\section{Research Methods}

Knowledge sharing is a context-embedded process, making its measurement difficult, and there is so far no standard method to measure the sharing process.

With the aim of understanding the knowledge flow/transfer and the learning processes between foreign companies and local universities in Thailand, we will undertake a qualitative approach. This entails there have been semistructured interviews with managers and workers of different companies. The questionnaire was administered at two selected companies in Thailand. The company was selected because it is widely known to have workforce of international managers and Thai workers.

The companies have been selected so that they represent a good sample of multinational companies in Thailand. The workforce sample includes a cross-cultural array of individuals. The items in the questionnaire were first analyzed using a pilot study that was conducted to measure the reliability and the validity of questions on the questionnaire. The questionnaire consisted of 25 items to which the 6-point Likert scale was applied for measuring purposes in order to avoid midpoint answering very much typical for Asian people overall.

Questions in the questionnaire were bilingual (English and Thai) so that to make sure there are no language barriers for any type of workers. The econometric model developed by (Shih and Chinerawat, 2009) was used here based on the expanded framework of the Herzberg's Two-Factor Theory (1959).

Reliability and validity of the questionnaire were tested using Cronbach's alpha, for which the value above 0.6 was treated as adequate (Nunally, 1978).

The model accounted for extended cross-cultural satisfaction by means of adding demographic factors into Motivation and Hygiene factors. The model found that Demographic factors, such as people from different regions of a host country, impact crosscultural satisfaction. The researchers also had interviews with individuals from different companies so that the data from the questionnaire can be validated as true and fair.

The dependent variable here measures self-assessment in terms of cross-cultural working satisfaction. Independent variables were categorized into Motivation Factor group, Hygiene Factor group, and Demographic Factor group. 
The first group - Motivation Factor variables (Xi) include: Challenge, Recognition, Personal Growth, Achievement, and Career Advance.

The second group - Hygiene Factor variables (Xj) include: Job Security, Status, Pay Competitiveness, Fringe Benefits, Safety, Working Conditions, Quality of Supervision, and Interpersonal Relations.

And finally the third group - Demographic Factor Variables (Xk) include: Age, Gender, and Education, Years of Service, Training Days, Working Hours, Salary Rate, and Income Package.

\section{Hypotheses}

Since the working environments and the demographics in companies A and B differ a lot, the following hypotheses have been developed:

Hypothesis 1: There is a difference in self-assessment of satisfaction in cross-cultural working environments of companies $\mathrm{A}$ and $\mathrm{B}$.

Satisfaction has a positive effect on individual performance, thus the following hypotheses have been put forward to explore the factors impacting satisfaction in the crosscultural working environment:

Hypothesis 2.1: Motivation factors, Hygiene factors, and Demographic factors have significant impact on satisfaction in the cross-cultural working environment of company A.

Hypothesis 2.2: Motivation factors, Hygiene factors, and Demographic factors have significant impact on satisfaction in the cross-cultural working environment of company B.

\section{Research Findings}

The data collection instrument for this research was a questionnaire adopted from several researchers and partly developed by the authors with the assistance of the human resource heads of the target company. The developed questionnaire aimed to measure the cross-cultural management outcomes and antecedents of the selected multinational enterprise in its operations in Thailand.

The hypotheses will be tested by performing a series of multiple regression analyses. All statistical tests will be carried out at a 5-percent significance level. We will test the hypotheses for implicit and explicit knowledge. Multiple-regression analysis provides statistical results showing how much of the variance in the dependent variable can be explained when several independent variables are examined (Punch, 1998).

In the multiple regression equation, various values for the dependent variable are predicted by the corresponding values for the independent variables when the intercept and regression coefficients are constant. In addition, the analysis also statistically computes the estimate effect of each independent variable on the dependent variable while simultaneously controlling for the effects of other independent variables (Singleton, Straits, and Straits, 1993). Expatriates play a significant role in transferring firm-specific tacit knowledge toe subsidiary businesses, and are needed for better performance at both the subsidiary's and the headquarter's level.

Cultural distance between different national categories of employees can stop the knowledge transfer and integration process, as the results of this study suggest. The expatriate participants reported that personal conflicts among Thai local staff were also a critical problem, especially when working as a team. 


\section{MANAGING CROSS-CULTURAL DIFFERENCES IN}

Both foreign and Thai respondents also reported their dissatisfaction when Thai local employees did not get along with each other and played politics among themselves. The findings of the surveys show there is lack of mutual understanding of the language. Multinational corporations need to find ways to effectively transfer knowledge among different groups of employees, especially in culturally distant subsidiaries, and take measures to increase cooperation, coordination and communication among them.

A practical implication that may result this performance problem can be to focus on effectively localizing subsidiaries in culturally distant locations. Moreover, even if compressing the pay levels between the host country nationals and the expatriates is not a feasible objective, perceived opportunities in multinational corporations can decrease the level of frustration among the host country nationals, and facilitate increased communication among these groups.

Interestingly, with respect to the degree of empowerment, Thai subjects reported their observations about different working styles among their different foreign bosses. Expatriates who had been working with Thai employees for a while would begin to understand, calm down, and be more patient with the Thais when work procedures did not go as planned and the job outcomes did not come out as expected.

\section{Discussion}

Thailand might be defined as a defender since its organizations have narrow productmarket domains. Top managers in this type of organizations are professional experts in their limited area of operations, they often do not tend to search outside of their domains for new opportunities. This may result in the narrower focus; these organizations rarely need to make major adjustments in their technology, structure, or methods of operation. Instead they focus mostly on improving the efficiency of their existing operations.

The findings of our surveys show there is lack of language understanding (namely, Thai vc. English). Furthermore, attitude and prejudice problems may emerge due to receiving inaccurate information about cultural and work-related values. Different perceptions and misinterpretation of verbal and nonverbal cues and also lack of trust and openness in communication were among the key problems too. All these problems have led to the inability to express well what they really wanted from each other so that to achieve quicker their individual and company's goals.

\section{Recommendations}

As this study has been conducted in Thailand it is limited to multinational companies operating in this country only and but our results can be further used for other, similar studies around the world. It would be advisable for researchers to have a few more companies examined so that to have better understanding of the cross-cultural differences in multinational corporations.

This study has been limited to the surroundings of Bangkok only. This can be treated as a limitation of our research. Further studies can be made on corporations in other Thailand's provinces too. The sample of our study was very small portion, as compared to the overall number of corporations operating in Thailand. Researchers can use other tools for analysis to have a better understanding of differences in cross-cultural multinational corporations. 
The cross-sectional design of the study may also pose some limitations. The impact of expatriate staffing on performance may not always be immediate, but may take time to materialize. The results should be interpreted with this reserved possibility in mind, and future attempts may use a longitudinal design to capture the effect over time. In later studies researchers can try use alternative measures capturing cultural distances.

A staffing pattern may have more positive performance outcomes than ethnocentric staffing patterns because of the diversity created out of this diverse staffing composition. We hope that the information presented in this paper will be beneficial for both expatriates and Thai employees in the course of learning each other's understandings, needs, and expectations. It is hoped that information presented in this paper can trigger more thoughts and generate further discussions in international/intercultural business communication classrooms.

When dealing with foreign managers, Thai workers need to be more open about their feelings and concerns, more direct, more rational, and more accountable not only for what to do but also for what not to do. To gain acceptability and trustworthiness from expatriate managers, the Thais must demonstrate intellectual capacity, high sense of responsibility, and self-motivation. When dealing with "difficult" expatriates who place stronger emphasis on task performance, Thai employees need to be more responsible for their own actions, particularly in what concerns time management. Expatriates should discard the belief that their own cultural norms and values are superior to those practised in a host country.

Foreigners should learn to open their mind and first get to know Thai local staff better, taking into account personal characteristics, area of work interest and expertise, personal problems, previous work problems and so on. Usually, it is the expatriates on their first term of overseas assignment reporting to have difficulties in adjusting to the host country culture.

Those who had worked outside the country before reported fewer difficulties in dealing with local employees. Punctuality is one of the most appreciated features by expatriates. The study also provides a framework for further investigation of commonalities and differences in tactics for dealing with international/intercultural communication problems at work in other countries as compared with those found in Thailand.

It is important to develop some sort of initial awareness of intercultural differences by demonstrating such positive attitudes as willingness to understand and adjust to a host country's culture, openness to presentation of different opinions, willingness to accommodate differences, showing respect to local employees and being a good role model. The expatriate should also demonstrate other positive personal attributes, such as being hard-working, polite, open-minded, honest, friendly, and patient.

\section{Conclusion}

To sum up, human resource management and its investigation have become the integral part of the firms' business strategies while they are trying to reach competitive advantage. Southeast Asian countries are greatly influenced by their national factors, sometimes traditional cultural influences become significant deterrents for the development of human resource management practices in these countries. The ongoing process of globalization has brought about many serious changes to this field. In the competitive world of globalization and workforce diversity, effective cross-cultural management is the key factor determining the success of multinational enterprises. This statement is supported by cross-cultural 


\section{MANAGING CROSS-CULTURAL DIFFERENCES IN}

management research in a leading consumer goods multinational enterprise which is successfully operating in Thailand nowadays.

Employee engagement could be regarded as one of the most essential characteristics of the organization, as it is the factor of direct influence on the effectiveness and survival of organization. This is because any organization not only needs to recruit qualified employees but also needs to maintain these employees by promoting their sense of belonging and employee engagement, the latter two being the useful attribute of organization's achievements. Furthermore, the multiple regression results also suggest that employee engagement can be enhanced by the existing collectivist culture, by means of stronger job security, by encouraging participation of employees, as well as by providing extensive training and more development opportunities for them.

The results of the study could be applied in management of multinational companies, more specifically - when emphasizing the promotion of employee engagement in overseas branches. Top management of multinational firms should put efforts into training and development in order to strengthen the organization's collectivist culture, and emphasizing employee participation and career stability. Engaged employees will definitely collaborate more to achieve good organizational performance. Several intercultural communication problems were found to be related to Thai employees' mentality and accountability, task assignments, time management issues, language deficiency, and personal/work relationships. Practical management tactics in dealing with these problems were suggested by expatriates and Thai senior supervisors who participated in this study.

Thai employees need to be more responsible for their own actions, particularly in what concerns time management. Punctuality will be most appreciated by expatriates. Thai local employees felt that expatriates tended to stereotype all Thais as being lazy. The locals commented that expatriates tended to be bossy and sometimes jumped to conclusions without thinking about the local cultural and environmental differences. Expatriates should discard the belief that their own cultural norms and values are superior to those in the host country.

Thai workers also need to become more flexible with each expatriate's working style, to develop self-dependency, and finally to recognize individual and cultural differences among different expatriates (just as there are differences between the Thais themselves). When dealing with foreign managers, Thai workers need to be more open about their feelings and concerns, more direct, more rational, and more accountable not only for what to do but also for what not to do.

The authors of this text hope that information presented above can be beneficial for both expatriates and Thai employees in learn each other's needs and expectations.

\section{References}

Bennett, R., Aston, A., \& Colquhoun, T. (2000). Cross-cultural Training: A Critical step in ensuring the success of international assignments. Human Resource Management, Summer/Fall, 39 (2 \& 3). 239-250.

Brewster, C., and Scullion, H. (1997). A Review and Agenda for Expatriate HRM. Human Resource Management Journal, 7. 32-41.

Bonache, J., Brewster, C. \& Suutari, V. (2001). Expatriation, A Developing Research Agenda. Thunderbird International Business Review, 43. 3-20. 
Chinerawat V. (2009). An Econometrical Three Factor Model of Cross-cultural Adaptability: A case study of Taiwan companies in Thailand. Graduate Institute of International Workforce Education and Development, National Taiwan Normal University, R.O.C. Taiwan.

Caligiuri, P.M. (2000a). Selecting Expatriates for Personality Characteristics, A Moderating Effect of Personality on the Relationship between Host National Contact and Cross-cultural Adjustment, Management International Review, 40, 61-81.

Caligiuri, P.M. (2000b), The Big Five Personality Characteristics as Predictors of Expatriates' Desire To Terminate the Assignment and Supervisor-rated Performance. Personnel Psychology, 53. 67-89.

Cullen, J.B. \& Parboteeah, K.P. (2008). Multinational Management: A Strategic Approach. South Western Publisher, USA.

Delios, A. \& Bjorkman, I. (2000). Expatriate Staffing in Foreign Subsidiaries of Japanese Multinational Corporations in the PRC and the United States. International Journal of Human Resource Management, 11, 278-293.

Fons Trompenaars and Charles Hampden-Turner, (1997) Riding the Waves of Culture: Understanding Cultural Diversity in Business (2nd ed.), 1, London: Nicholas Brealey

Gao, Q., Fjelkner, V. \& Lange, G. (2005). Preventing expatriate failure - A research on the expatriates selection and training. Retrieved November 3, 2009.

Gong, Y. (2003). Subsidiary Staffing in International Enterprises, Agency, Resources, and Performance. Academy of Management Journal, 46. 728-739.

Harzing, A.W. (2001). Who's in Charge? An Empirical Study of Executive Staffing Practices in Foreign Subsidiaries. Human Resource Management. Summer, 139-158.

Herzberg F. (1959). Herzberg's theory. Retrieved February 23, 2010.

Hofstede, G., (2001). Culture's Consequences: Comparing Values, Behaviors, Institutions and Organizations across Nations. Thousand Oaks, CA: SAGE Publications.

Institute of Asia Study. (2005). Thai workers Protest in Taiwan. Retrieved February 23, 2010 from http://www.thaiworld.org/th/include/answer_search.php?question_id=184

Kim, Y. Y. (2004), Long-term cross-cultural adaptation: Training implications of an Integrative theory, In: D. Landis, J. Bennett \& M. Bennett (Eds.). Handbook of Intercultural Training. Thousand Oaks, CA: Sage.

Kim, Y. S. (2009) A Study of Cross-Cultural Adaptation Communication Experiences of American Expatriates in South Korea. Human Communication. A Publication of the Pacific and Asian Communication Association, 11(4), 511-528.

Lau, K., Nicholas, S., O Flynn, J., Ricciotti, A., \& Sammartino, A. (2001) Expatriate Management : A Business Model for diversity management. Retrieved from

http://www.managementmarketing.unimelb.edu.au/mcib/include/diversity/EXPATRIATE\%20MAN AGEMENT\%20-\%20A\%20BUSINESS\%20MODEL \%20FOR\%20DIVERSITY\%20MAN.pdf

Mendenhall, M.E., Dunbar, E. \& Oddou, G.R. (1987). Expatriate Selection, Training, and Careerpathing, A Review and Critique. Human Resource Management, 26, 331-345.

Punch, K.F. (1998). Introduction to Social Research: Quantitative \& Qualitative Approaches. London: Sage Publications.

Selmer, J. (2000). A quantitative needs assessment technique for cross-cultural work adjustment training. Human Resource Development Quarterly, 11(3), 269-281.

Schuler, R.S., Budhwar, P. \& Florkowski, G.W. (2002). International Human Resource Management, Review and Critique. International Journal of Management Reviews, 4. 41-70.

Singleton Jr., R.A.; Straits, B.C. \& Straits, M.M. (1993). Approaches to Social Research, 2nd ed., Oxford: Oxford University Press.

Smith, P. B., M. F. Peterson \& Thomas, D. C. (2008). The Handbook of Cross-Cultural.Management Research. Los Angeles: Sage Publication. 


\section{MANAGING CROSS-CULTURAL DIFFERENCES IN}

The Thailand Board of Investment (2008). Investment Direction in Thailand 2008. Thailand Investment Review, 18(2), 9-10.

Tung, R. (1982), Selection and Training Procedures of US, European, and Japanese Multinationals, California Management Review, 25. 57-71.

Windham International and National Foreign Trade Council, Inc. (1998). Global relocation trends: 1998 survey report. New York: Windham International.

Paper submitted

Paper accepted for publishing

Paper published online
18 January 2018

23 March 2018

15 June 2018 